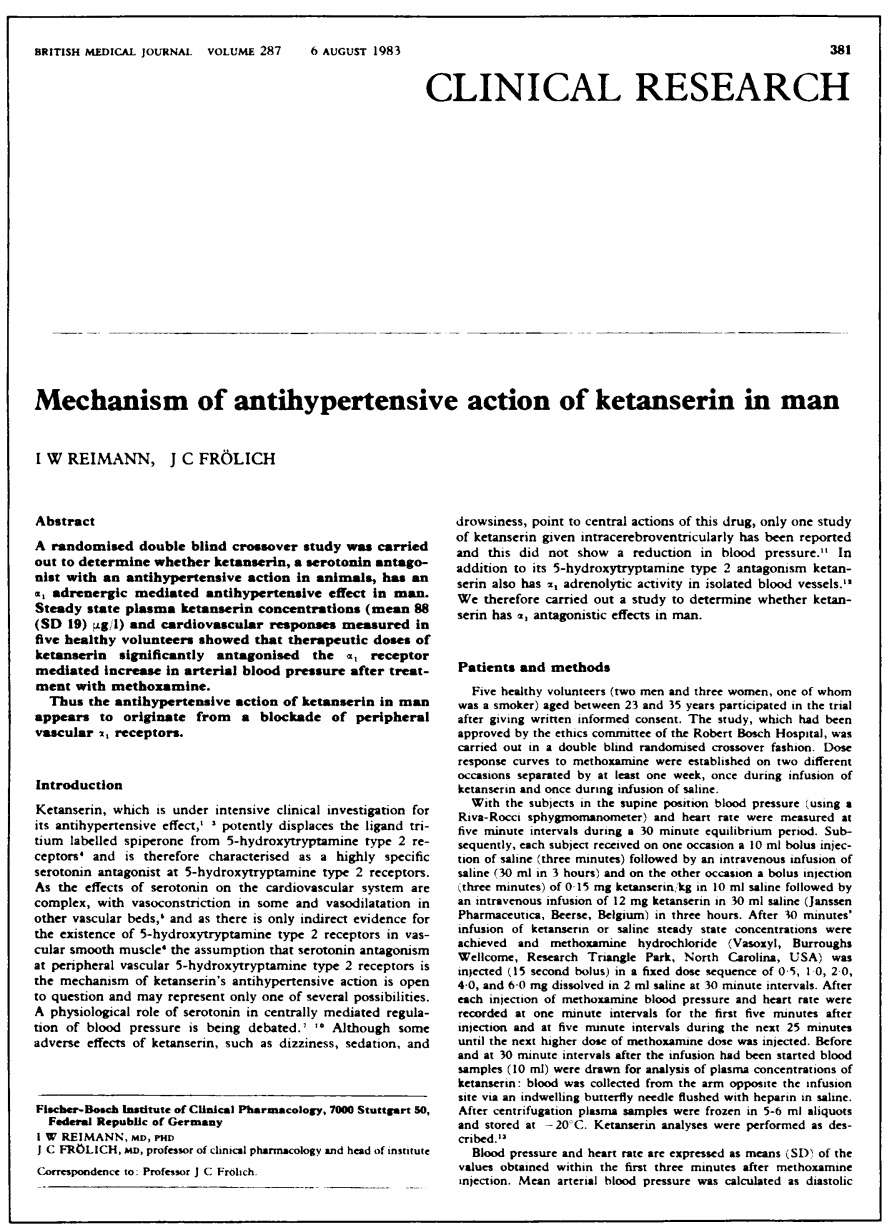
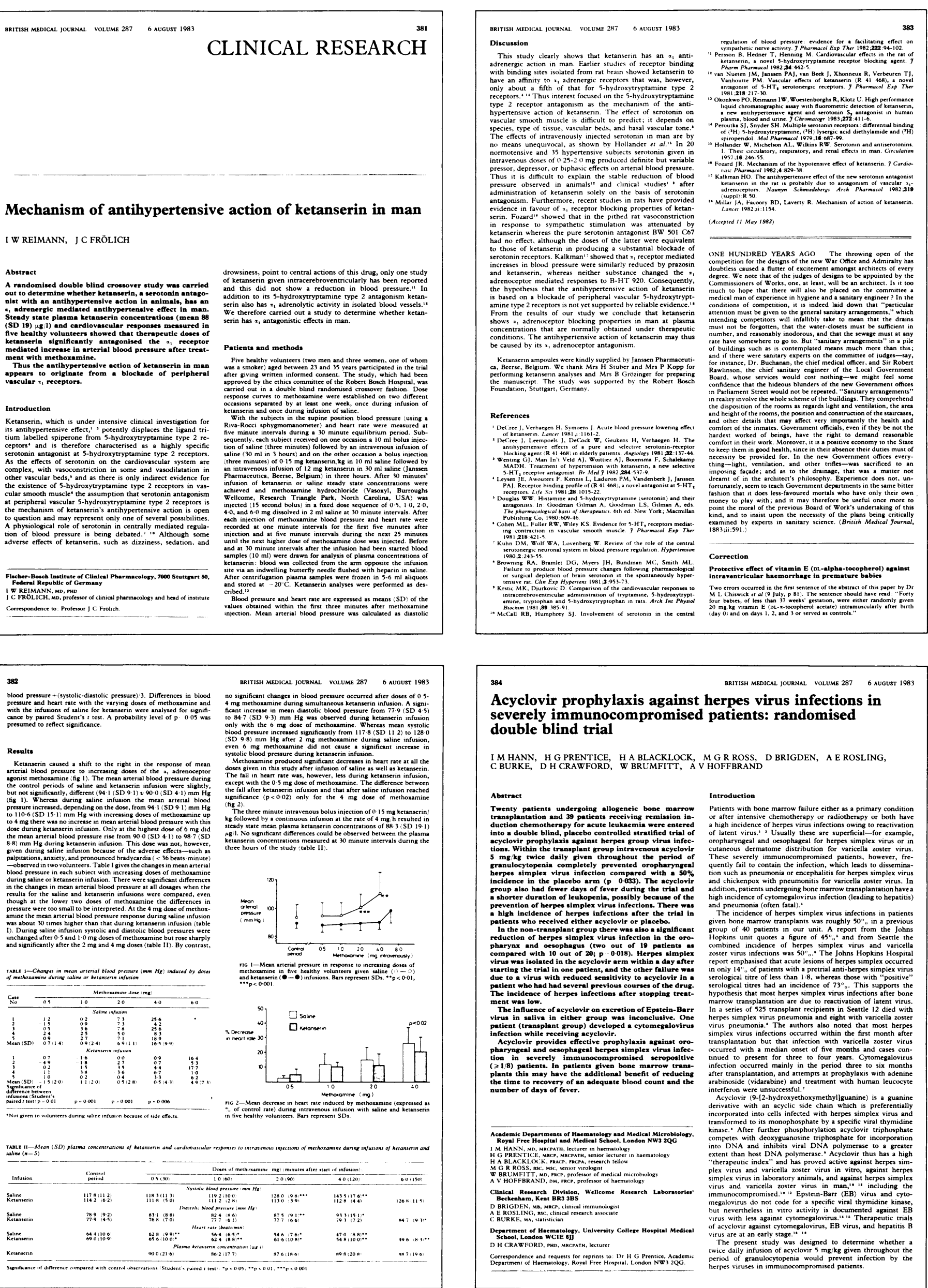

\section{4 Acyclovir prophylaxis against herpes virus infections in severely immunocompromised patients: randomised double blind trial}

I M HANN, H G PRENTICE, H A BLACKLOCK, M G R ROSS, D BRIGDEN, A E ROSLING,
C BURKE, D H CRAWFORD, W BRUMFITT, A V HOFFBRAND

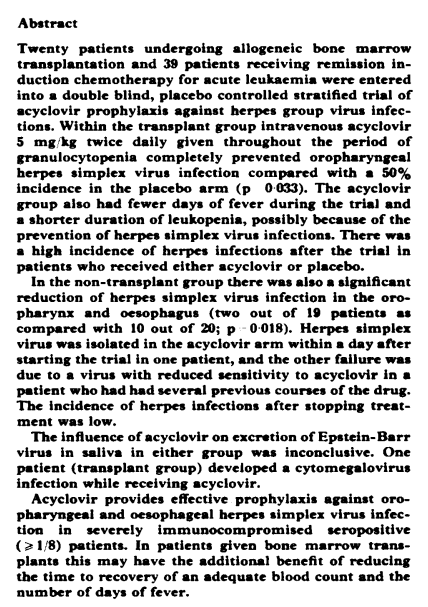

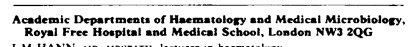

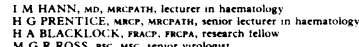

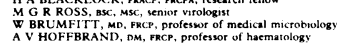

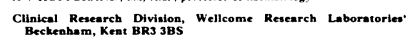

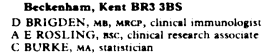

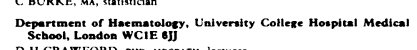

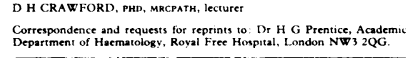

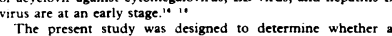

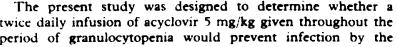




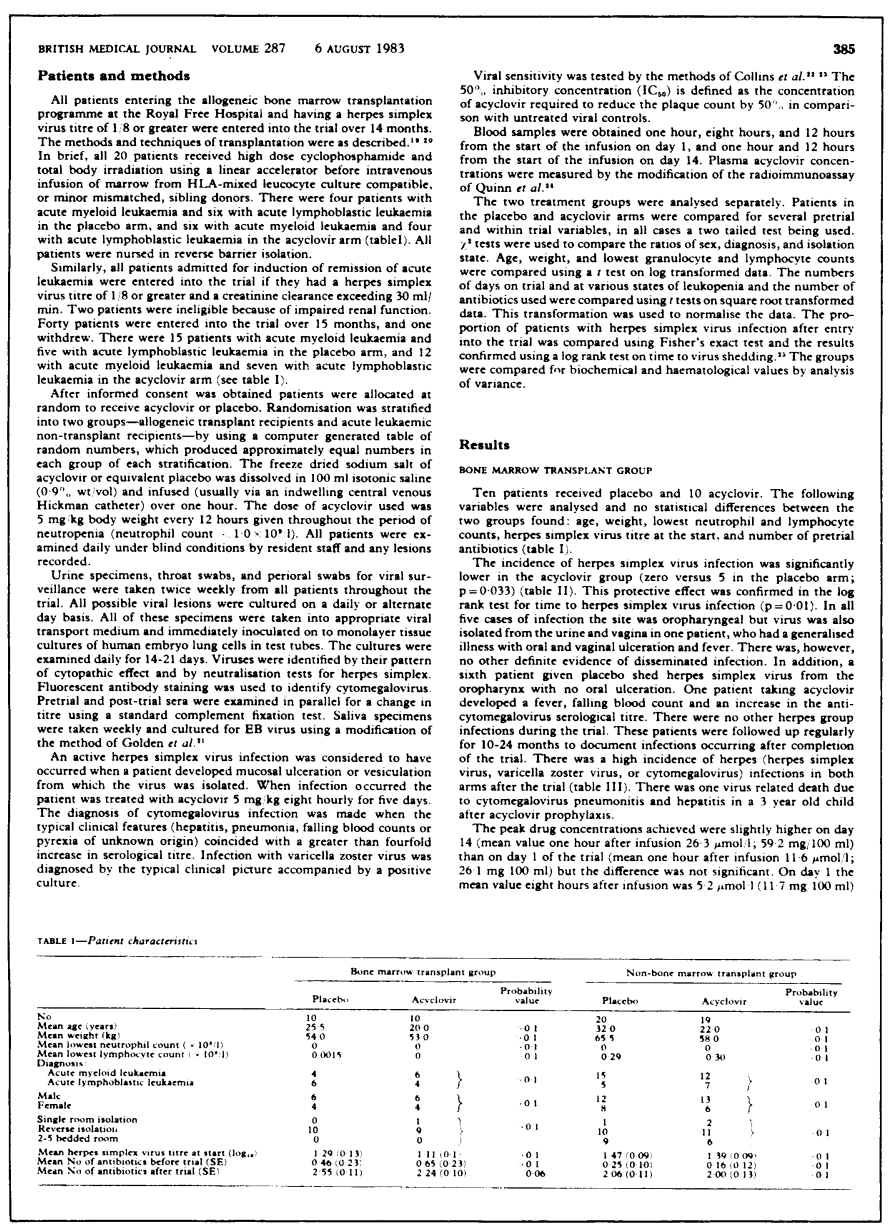

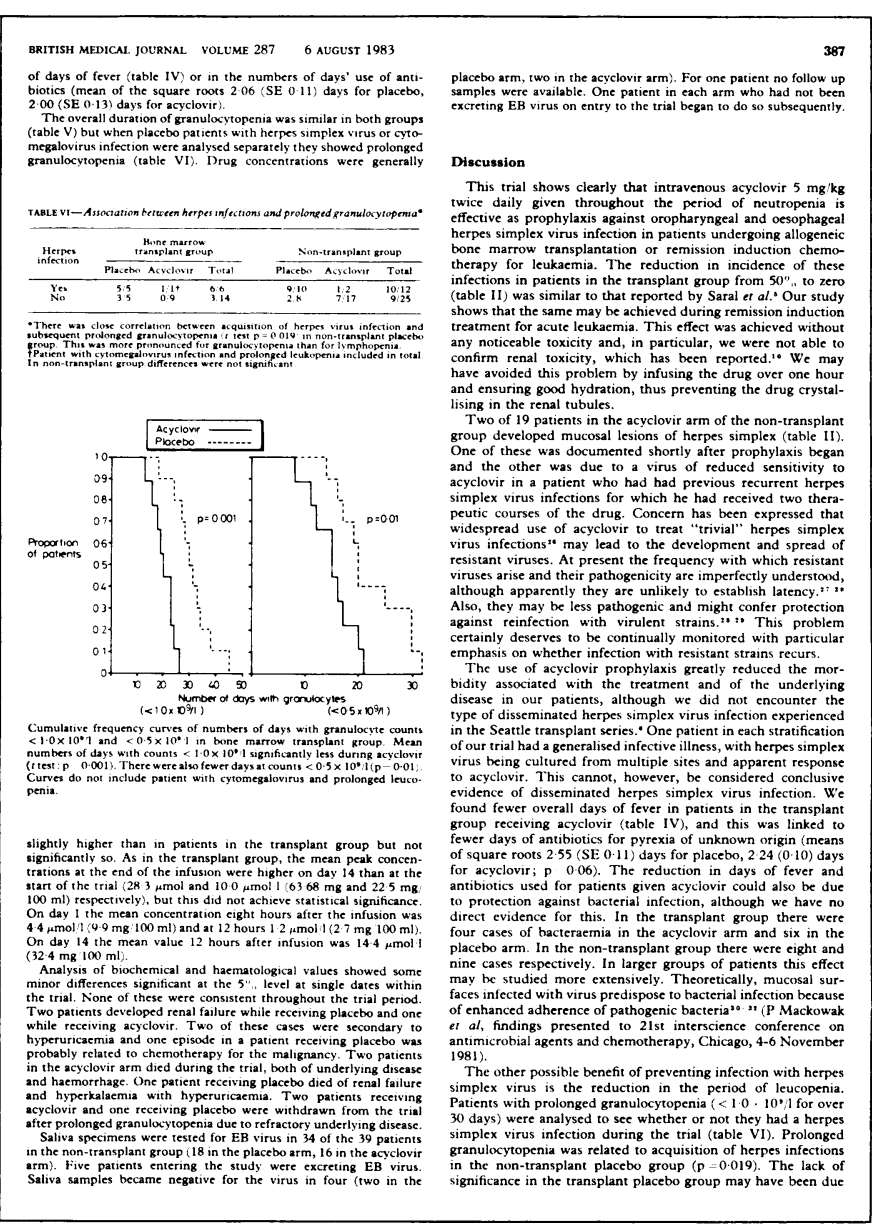

\section{8}

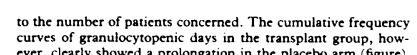

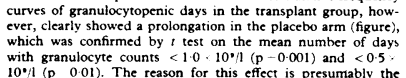

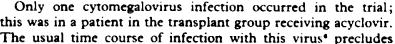

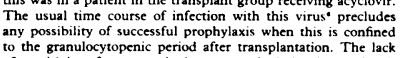

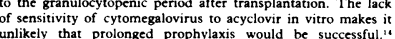
unlikely chat prolonged prophylaxis would be successulul.t
Similarly, infection with varicella zoster virus may occur up po

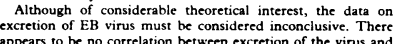

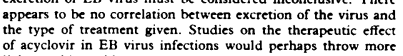
light on this problem.
Acyclovir does not prevent latency of herpes simplex virus,

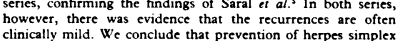

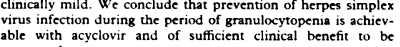

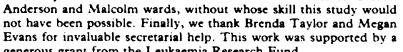
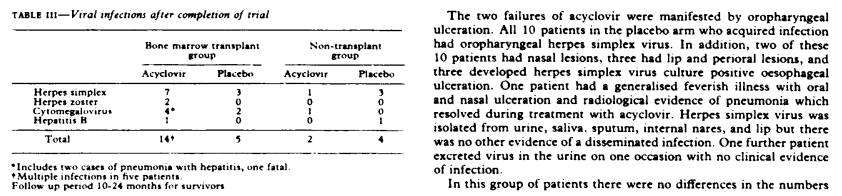

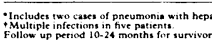

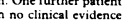

\begin{tabular}{|c|c|c|c|c|c|c|}
\hline & \multicolumn{3}{|c|}{ Bone matrow trangriban arour } & \multicolumn{3}{|c|}{ Ninn-transplatri a truer } \\
\hline 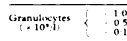 & 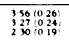 & 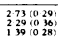 & 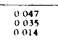 & 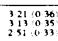 & 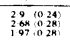 & \\
\hline 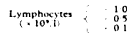 & 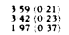 & $\begin{array}{lll} & \end{array}$ & 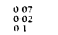 & 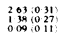 & 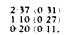 & \\
\hline
\end{tabular}

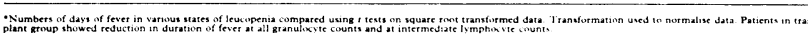

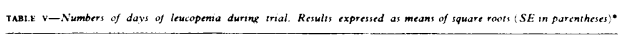

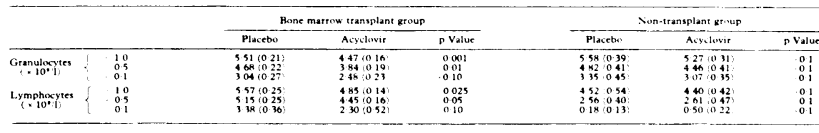

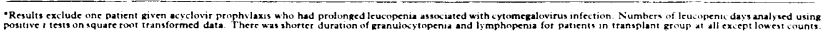

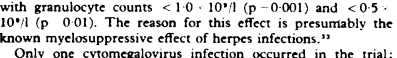

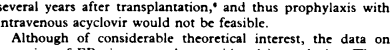

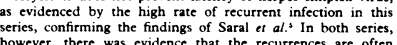

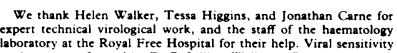

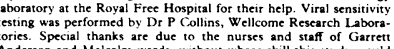

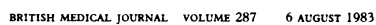

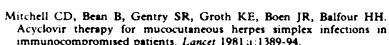

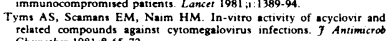

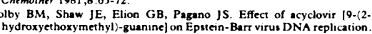

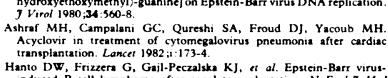

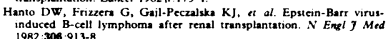

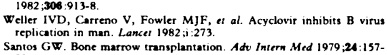

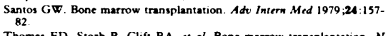

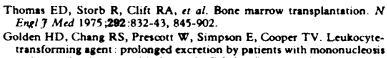

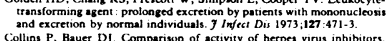

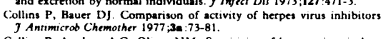

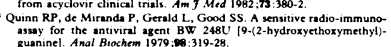

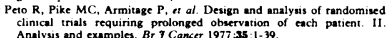

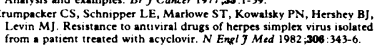

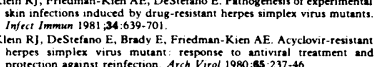

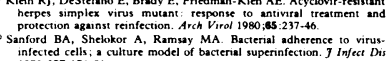

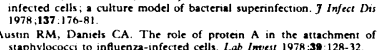

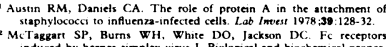

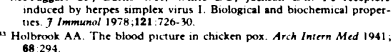

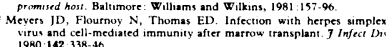

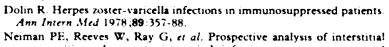

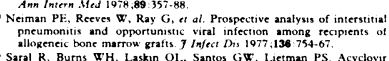

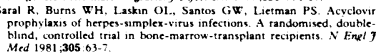

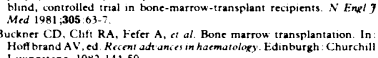

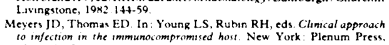

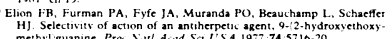

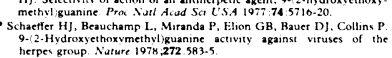

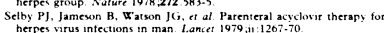

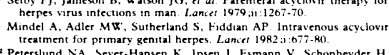

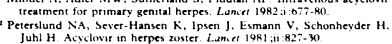

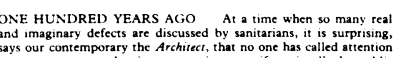

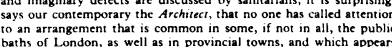

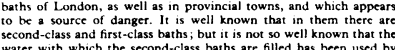

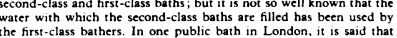

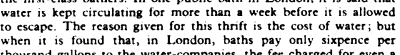

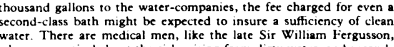

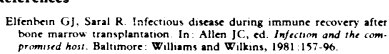

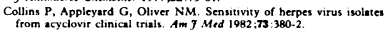

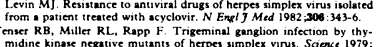

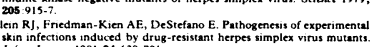

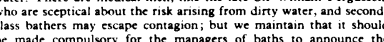

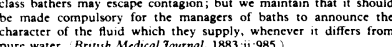

